\title{
Entrepreneurship development matrix in the energy sector
}

\author{
Lyubov Manukhina ${ }^{1, *}$ and Larisa Prykina ${ }^{1}$ \\ ${ }^{1}$ Moscow State University of Civil Engineering, Yaroslavskoeshosse 26, Moscow, 129337, Russia
}

\begin{abstract}
The conceptual idea of entrepreneurship is usually based on the need to carry out initiative activities aimed at profit making (acquisition of personal income). It means production of new or improved types of goods, energy resources and services based on technological and organizational innovations in the energy industry. Ways of boosting the productive system from its lower level of organization to a higher one are substantiated. For this purpose, all the factors of the state of internal and external activity environments must constantly be within the limits of allowable entrepreneurial niches, i.e. allowable calculated values. The conceptual idea should: ensure output of products, works and services that meet the receiver's requirements in terms of the quality, increase marketability, ensure implementation of envisaged programs, increase economic efficiency, ensure the compliance of the entrepreneur's opportunities. Such compliance can be achieved through a detailed system development of a combination of the above factors. For example, through strategic planning of activities using entrepreneurship matrix assessment based on cluster organizational models. Rational ways of entrepreneurship development in the energy sector should be chosen on the basis of the analysis of its cluster, matrix components.
\end{abstract}

\section{Introduction}

Entrepreneurship is a special type of economic activity, the essence of which is to stimulate and satisfy public demand for the specific needs of its members. It is done through market exchange and focus on gaining specific advantages by means of market distortion [1].

In other words, entrepreneurship means that entrepreneurs have such concepts, knowledge, creativity, and abilities that would allow formulating the properties of innovation in their activities, turning the idea into an economically grounded reality.

According to Vladimir Dal: "An entrepreneur starts, decides, uses a new business to accomplish something significant" [2].

The main features of entrepreneurship are as follows [3]:

- Initiative in economic activities under conditions of economic freedom and uncertainty.

- Commercial risks caused by instability and uncertainty of market conditions.

\footnotetext{
*Corresponding author: 4804107@mail.ru
} 
- Innovation in terms of practical changes in market conditions (situations) using various types of creative innovations (paradigms).

So, entrepreneurship is a special type of stimulation and satisfaction of market exchange based on the advantages of ways to change their level of equilibrium.

In practice, the entrepreneurial idea is implemented in the following three forms of economic activity: state entrepreneurship, private entrepreneurship, and corporate entrepreneurship.

The business environment is divided into external and internal ones [4].

The external environment is a set of conditions and factors affecting the development of entrepreneurship, acting independently of the will of entrepreneurs. It includes the following subsystems:

- Economic situation.

- Political situations of society and state development sustainability.

- Legal environment with the establishment of rights, obligations, liability.

- Social situation related to the level of effective consumer demand and the unemployment level.

- Cultural environment associated with the level of education.

- Scientific and technological, process environment.

- Government regulation and entrepreneurship support.

\section{Experimental section}

The relationship of goals and end results represents the basic principle of assessing the effectiveness of entrepreneurial activity (Fig.1.) [5].

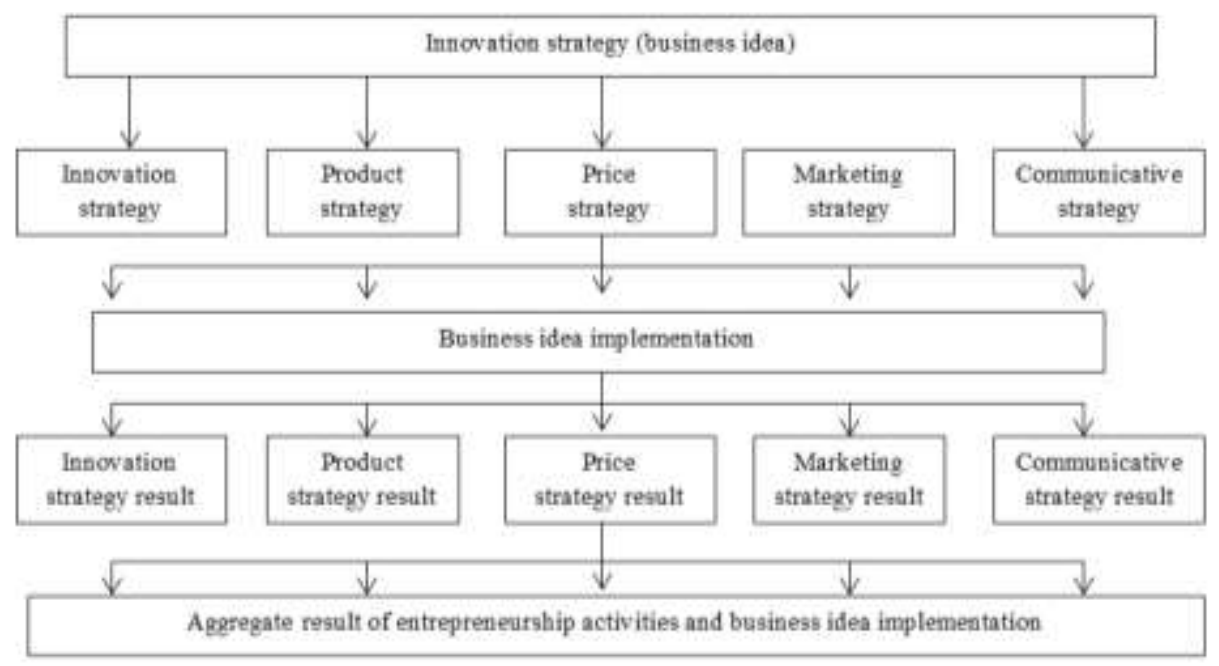

Fig. 1. System of interaction of the goal and the end result of entrepreneurship activities.

According to D. Meadows: "A system is an interconnected set of elements that is coherently organized in a way that achieves something (function or purpose)". In our case, the aggregate result of entrepreneurship activities is their effectiveness under conditions of work of innovation strategy with direct and inverse links. In this case, the innovative idea of the entrepreneur should be directed to the description and cognition of the productive system with its direct and inverse links. It represents "something more than a simple set of 
elements" [6]. It is this "more" that the entrepreneur must foresee and use in their activity. A. Einstein wrote the following about this: "We cannot solve our problems with the same thinking we used when we created them. You have to rise above it to the next level". What transitions from one level to another should be considered by the entrepreneur when developing the ideology? What types of direct and inverse links should be combined? Entrepreneurial research shows that such links are the following three systems of development: self-fulfillment, self-preservation (self-regeneration), and their coordination [7].

Therefore, the strategy of entrepreneurship can be divided into two stages: development, selection of new ideas, knowledge, creativity as the stage of innovations, and introduction of innovations into practical activities. Entrepreneurship combines creative possibilities of the entrepreneur with the needs of the market or, conversely, the combination of the needs of the market with the creative possibilities of entrepreneurship. In this regard, the elements of a life cycle or a new project pass through a round of entrepreneurial ideas (Fig. 2).

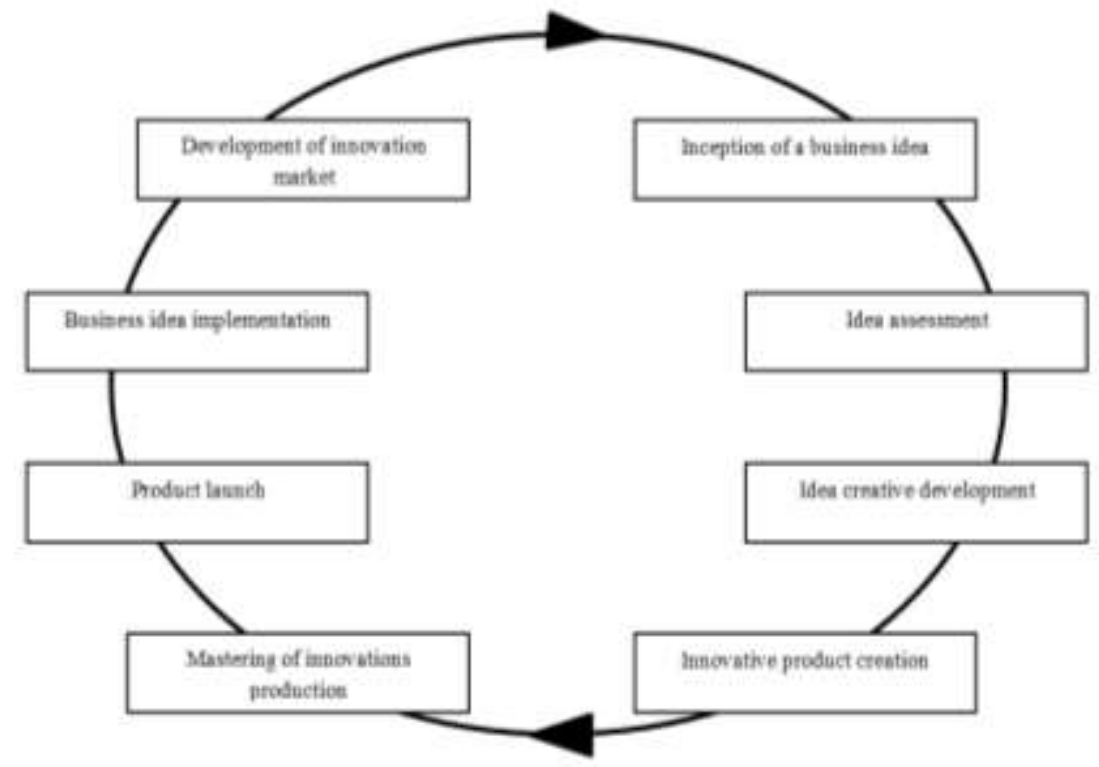

Fig. 2. Round of the life cycle of a business idea (according to A. Asaul).

Effective business results as the ratio of results and goals are achieved through a rational combination of entrepreneurship and creativity of the entrepreneur. Three arrows (selforganization, self-preservation, and their coordination) must be combined with their system operation. The total energy of these arrows corresponds to their initial potential (Fig. 3) $[8,9]$.

The principles of entrepreneur's successful activities are expressed by the following actions:

1 - self-organization of structures of integral formations due to the selection of their interconnections, interformations, intercorrelations on the basis of the technologies selected by nature. So, integrity generates free energy in the form of its economy (PP1, P1P2, PP2).

2 - self-support of integrity structures through self-consumption (0PP2) of free energy previously generated. So, the life cycle (LC) increases.

3 - coordination of processes of self-organization and self-support through integral formation (as its mind, creativity, skills, learning) of entrepreneurship, copying of natural technologies without leaving the limits of its energy potential P (PKP2area) [11]. 


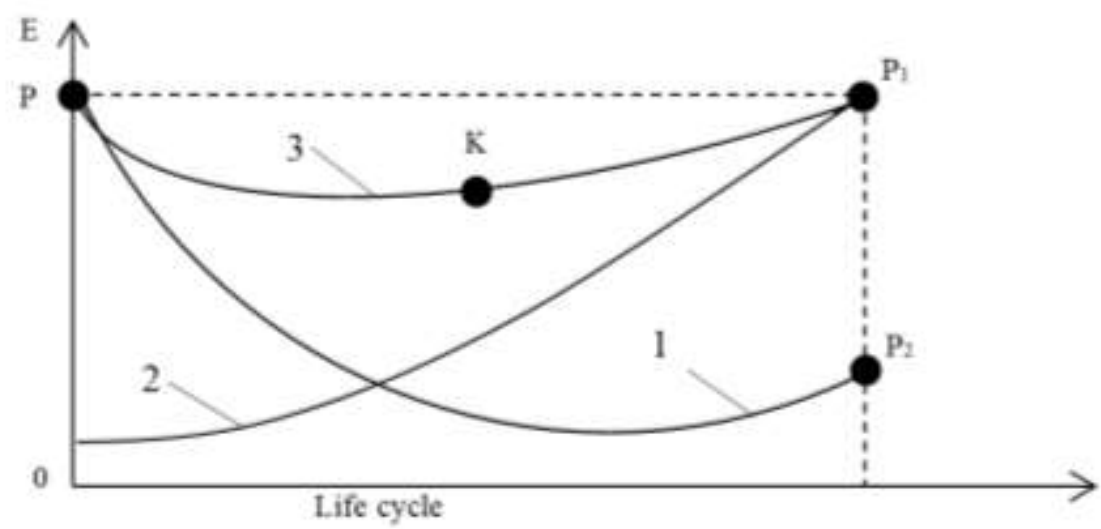

Fig. 3. Conditions for successful entrepreneurship activities: where $E$ is the energy of entrepreneurial system state (for example, in the form of initial capacity) with its energy potential $\mathrm{P}$ and the state of business idea development arrows; 1 - self-organization of business model (idea) structures; 2 - selfsupport (self-preservation) of model integrity during its operation; 3 - entrepreneurial creative actions on arrows coordination [10].

To cope with conditional, unconfirmed by nature actions, the entrepreneur (business entity) shall base their activities on technological, organizational, and economic innovations.

We cannot ignore the conclusion obtained by A. Chizhevsky (XIX century): "Science is knowledge about the measured. The direct problem of the future is to make economics a science, not a conditional fairy tale, by freeing it from metaphysics, from the arbitrariness of subjectivism, from everything not measured, give it, as well as its sister - sociology, measuring units and laws".

The use of entrepreneurship cluster organization should be considered as one of the methods of human activity systematization [12].

\section{Discussion}

A cluster is an organizational structure that unites integrating networks of interaction of individual units into spheres (areas) with the aim of increasing their flexibility, adaptability, and mobility [13].

A cluster is a tool of activity of business organizations with the following main features (according to M. Porter):

- Geographical unity.

- Technological unity.

- Economic unity.

As noted above, the results of cluster organization of entrepreneurship are achieved in the form of a combination of the principles of its development along three arrows (selforganization, self-support, and their entrepreneurial coordination) and bringing its effectiveness to the area of an entrepreneurial niche (EN) within the constant unchanged initial energy potential of the analyzed integrity [13].

Humans are biological thinking machines, agents of nature; they have two types of potentials - the original unchangeable one and the changeable one - due to natural cycles of interconnected multi-layer internal and external structures (environments) [14]. The initial required unchangeable energy potential of natural integrity can be represented as a zero time axis, in relation to which the agent works in the space-time system and in relation to 
which the exchange of resources in the form of energy between them is assessed, the state of which has a constant quantitative niche in the form of energy potential.

At the beginning of activity analysis, it is necessary to single out "diametrically opposed" vectors in human life that used to choose (achieve) the organization of progressive equilibrium.

When considering only basic provisions of the unity of systemic activity, we immediately come across distortions in human actions. When assessing their activities, they often do not take into account changes in the environment (curve 2) (see Fig. 3.). The following provisions [15] can be referred to the main exceptions and violations in the assessment of progressive equilibrium organization:

1. Violations in the reflection of human activity under conditions of the unity of nature systemic activity.

Only 1,000 years ago, Saint Thomas Aquinas noted the most important feature - the use of a double standard for the assessment of activities in the natural environment, from which a human cannot escape to this day: "Where the field of knowledge of natural law ends, the area of speculation on its ignorance begins".

The first standard (area - curve 1, (see Fig. 3.)) allows a person to get positive results from their activities. They walk in space, manage nuclear reactions, create nanotechnologies based on defect-free material structures, use mobile communications and computer simulation, create supersonic vehicles, erect high-rise buildings and skyscrapers, etc. All this is based on discoveries and the use of fundamental laws.

The second standard (area - curve 2) allows for erroneousness in human actions. They are mistaken (due to not using natural law to the fullest extent) and imitate (fake) the relationship between human activity and nature. An example of it is activity assessment by abstract, conditional, fragmentary, reflexive commensurators, for example, in the form of money and derivatives.

2. Partial consideration of the effects of human work in the ascending cycles of nature.

The whole real world retains its integrity due to the balanced work of its agents (and primarily humans).

Society depends on manifestation of the vector of the quality of the standard of living of a person. The synthesis and decay of energy states of the natural habitat determine system life cycles. However, when analyzing the standard of living, in most cases, humans take into account their actions and, to a smallest extent, actions of nature.

3. Partial consideration of the effects of human work in the ecological and synergetic interactions.

Energetics is associated with the laws of fundamental natural processes and phenomena of self-organization, self-preservation, and coordination with each other. The vector of the quality of life is based on the compliance of internal and external environments. The resulting inconsistency of actions in the human-nature system results in an accelerated destruction of their internal structures.

4. Possibility of using a universal system energy meter in assessing the quality of a person's standard of living.

Many researchers proved that energy is a system commensurator of the Universal activity in the processes of manifestation of progression and duration of development of systems and agents.

A. Einstein concluded: "Everything is energy and that's all there is to it" [16]. However, in human and public life, some caution and tardiness are observed in the use of energy as a universal meter.

Humans are genetically designed to receive and retain energy coming from the outside as long as possible and as efficiently as possible while contacting with environments. It allows saving themselves and contributing to the preservation of their surroundings. Energy 
plays the role of a universal commensurator of everything and everyone. The work of a person is connected with receiving and transforming, receiving and transmitting, distributing and using this energy.

5. The origin of crises as a result of difficulties in the coordination of human activity with activities of nature.

The description of a single and inseparable process of work of ecological, biological, and socio-economic systems using various commensurators causes errors, inaccuracies, and failures when comparing the results. Such trends also multiply when determining the quality and standard of living of a person. The consequence of it is destruction of production, an increase in the level of unemployment, generation of scholastic dogmatics, a decline in the level of education, etc. Emerging crises require revitalization of entrepreneurship.

The potential of the activity of an entrepreneur is sources, opportunities, funds, stocks that can be used to achieve a specific goal. The life of a person, society is based on the energy potential, which is divided into environments with certain vectors of their development: the vector of life activity, the vector of self-organization of their internal structures, the vector of resource consumption for the self-support of these structures, the vector of creativity, spirituality, rationality, collectivity, intelligence to accelerate life processes.

- The criterion (vector) of life expectancy, including biological integrities, is an integral indicator $\left(\mathrm{E}_{\mathrm{LC}}\right)$ covering the effects across the whole scale of life activity of biological formations $\left(\mathrm{T}_{\mathrm{LC}}\right)$ by aggregate interrelations $(\mathrm{W})$ of internal and external environments. The initial energy potential of life activity $\left(\mathrm{E}_{\mathrm{LC}}\right)$ must always be greater than the sum of the energy of internal and external environments:

$$
\mathrm{E}_{\mathrm{LC}}=\mathrm{F}\left(\mathrm{T}_{\mathrm{LC}}, \mathrm{W}\right)>0(1)
$$

- The vector of effects of self-organization of internal structures of a biological formation (VSO) - processes of creation, negentropy, harmonization, vitalism, uniqueness, innovation, infrastructure, complexity, adjustability, etc. It ensures system transition to a new qualitative state.

- The vector of self-support effects (VSSE) of internal structures through the consumption of free energy obtained during their self-organization (VSO) by replacing outdated structures. Consumption is absorption of free energy that was extracted by processes of self-organization of structures.

- The vector of experience in the development of natural technologies. Technology is an art, skill, human ability to select aggregate techniques and methods for obtaining, processing or reprocessing of raw materials, minerals, and semi-finished products. It requires the use of certain techniques, methods, and ways by their gradual selection. Technology leads to the desired results.

- Noospheric vector. According to V. Vernadsky: "The doctrine of the noosphere is a global project that transforms human activity on our planet as the most active part of the biosphere, as an important factor of its organization."

Consequently, the following factors have an impact on the effectiveness of the entrepreneur's activity: the level of knowledge of fundamental laws, the ability to create tools, infrastructures and conditions that ensure joint self-preservation of human life and nature. A human is engaged in a problematic search for harmony between fragmentariness and systematicity, between conventionality and reality, conservatism and innovation on the basis of renewable energy cycles. 


\section{Conclusions}

The real world fascinates us with its amazing achievements. It attracts entrepreneurs to use unlimited possibilities for the creation and operation of various types and forms of their activities. However, it is also necessary to learn the fundamental laws of nature, on the basis of which entrepreneurs must act. Humans are provided with nature, channels, fractals, codes that indicate rational ways for their development and self-preservation. We are convinced that humans learn the laws of entrepreneurship, and so they preserve themselves.

The entrepreneurial niche is expressed in the form of an area of location and combination of three types of resources used. This area decreases with an increase in the number of types of resources analyzed. The analyzed entrepreneurship depends on the initial potentials of each of the resources used. The intensification of entrepreneurship can be carried out at production parameters that do not go beyond the boundaries (limits) of the entrepreneurial niche.

The considered matrix of entrepreneurship assessment reduces risks of production and increases its efficiency.

\section{References}

1. L. Kauškale, I. Geipele, Procedia Engineering 172, 505-512 (2017)

2. H. Bossel, Ecological Modelling 63(1-4), 261-276 (1992)

3. P. Grabovy, A. Orlov, Procedia Engineering 153, 195-202 (2016)

4. S. Baronin, K. Kulakov, Journal of Advanced Research in Law and Economics 6(2), 291-298 (2015)

5. S. Okhotina, P. Kukhtin, L. Manukhina, MATEC Web of Conferences, 08074 (2017)

6. L. Prykina, A. Orlov, Procedia Engineering 165, 1388-1394 (2016)

7. H. Bossel, Ecological Economics 35(3), 337-355 (2000)

8. M. McCaffrey, L. Bylund, Journal of Business Venturing 32(5), 461-475 (2017)

9. B.Ş.E.H. Hobikoğlu, Procedia - Social and Behavioral Sciences 195, 1156-1165 (2015)

10. T. Narezhnaya, L. Prykina, IOP Conference Series: Earth and Environmental Science 19, 012141 (2017)

11. M. Josefy, R.M. Stevenson, Journal of Business Venturing (2018)

12. A. Dwivedi, J. Weerawardena, Journal of Business Research 86, 32-40 (2018)

13. K.W. Chau, S.K. Wong, C.Y. Yiu, H.F. Leung, Journal of Real Estate Literature 13(3) (2005)

14. L. Manukhina, L. Prykina, MATEC Web of Conferences 170, 01134 (2018)

15. O. Grigor'eva, A. Gerasimov, T. Skrebcova, Terra Economicus 11(1-3), 108-113 (2013)

16. S. Okhotina, P. Kukhtin, L. Manukhina, MATEC Web of Conferences 106, 08074 (2017) 